\title{
PENTINGNYA KETERLIBATAN ORANG TUA DI LEMBAGA PAUD DALAM MENSTIMULASI PERKEMBANGAN SOSIAL EMOSIONAL ANAK USIA DINI
}

\author{
${ }^{1)}$ Evi Desmariani, ${ }^{2)}$ Muzayyanah, ${ }^{3)}$ Jendriadi, ${ }^{4)}$ Widdya Rahmalina \\ ${ }^{1,2)}$ Program Studi Pendidikan Anak Usia Dini, STKIP Adzkia \\ ${ }^{3)}$ Program Studi Pendidikan Guru Sekolah Dasar, STKIP Adzkia \\ 4)Program Studi Pendidikan Matematika, STKIP Adzkia \\ 1,2,3,4) Jl. Taratak Paneh No 7 Korong Gadang, Kalumbuk, Kec. Kuranji, Padang - Sumatera Barat - Indonesia \\ E-mail : evidesmariani@stkipadzkia.ac.id,muzayyanah@stkipadzkia.ac.id, jendriadi@stkipadzkia.ac.id, \\ widdyarahmalina@stkipadzkia.ac.id,
}

\begin{abstract}
ABSTRAK
Tujuan sebagian besar orang tua memasukkan anaknya ke lembaga PAUD adalah agar anaknya bisa belajar membaca, menulis, berhitung, dan pandai mengaji. Tetapi, orang tua tidak memikirkan bagaimana perilaku anak selama berada di sekolah. Seperti yang terjadi di PAUD Terpadu Hauriyah Halum. Hal ini sering disampaikan guru kepada orang tua setiap anak pulang sekolah dengan harapan orang tua menasehati anak saat berada di rumah. Akan tetapi, dari hari ke hari tidak terlihat ada perubahan, bahkan semakin berlarut-larut. Karena itu, perlu dilakukan penyuluhan tentang pentingnya keterlibatan orang tua di lembaga PAUD dalam menstimulasi perkembangan sosial-emosional anak usia dini. Metode penyuluhan berupa ceramah dan tanya jawab. Pengabdian kepada masyarakat ini bertujuan supaya guru selalu melibatkan orang tua dalam mendidik anak, terutama dalam menstimulasi perkembangan sosial-emosional anak sejak usia dini. Sehingga anak bisa mengikuti proses pembelajaran dan berperilaku baik kepada guru dan teman selama berada di sekolah. Hasil dari pengabdian kepada masyarakat ini adalah orang tua dapat memahami perannya dalam menstimulasi perkembangan sosial emosional anak usia dini. Kerjasama yang baik antara guru dan orang tua serta keteladanan yang baik sangat berpengaruh dalam pendidikan anak usia dini.
\end{abstract}

Kata Kunci: stimulasi, sosial emosional, anak usia dini.

\begin{abstract}
The goal of most parents to take their children to go to kindergarten institutions is so that their children can learn to read, write, count, and be good at reading the Al-Qur'an. However, parents do not think about how the child's behavior while at school. Like what happened in Hauriyah Halum Integrated Kindergarten. This is often conveyed by the teacher every time the child comes home from school with the hope that the parents advise the child while at home. However, every day there is no visible change and even more protracted. For this reason, it is necessary to do counseling on the importance of parental involvement in kindergarten institutions in stimulating children's socio-emotional development from an early age. The extension method is in the form of lectures and questions and answers. This community service aims to ensure that teachers always involve parents in educating children, especially in stimulating children's social-emotional development from an early age. So that children can follow the learning process and behave well to teachers and friends while they are at school. The result of this community service is that parents can understand their role in stimulating the social emotional development of early childhood. Good cooperation between teachers and parents and good role models is very influential in early childhood education.
\end{abstract}

Keyword: stimulation, social emotional, early childhood

\section{PENDAHULUAN}

Minat orang tua untuk memasukan anak semenjak usia dini kelembaga PAUD semakin hari semakin meningkat. Ini semua dikarenakan orang tua sudah banyak menyadari akan arti pentingnya pendidikan yang dimulai semenjak usia dini. Sehingga orang tua berbondong-bondong memasukkan anak kelembaga PAUD yang terdekat dari tempat tinggal. Disamping itu perhatian pemerintahpun semakin hari semakin meningkat terutama dalam memfasilitasi semua kebutuhan anak yang sudah diberikan layanan dilembaga PAUD. Fasilitas yang diberikan pemerintah tidak hanya berupa sarana dan prasarana yang dibutuhkan dalam menstimulasi semua aspek 
perkembangan anak usia dini, akan tetapi juga bantuan untuk kesejahteraan pada pendidik yang mengabdi di lembaga PAUD berupa dana insentif sebagai penambah honor pendidik PAUD yang masih belum seimbang dengan tanggung jawab yang diemban setiap hari. Selain itu juga perhatian pemerintah terhadap arti pentingnya pendidikan anak usia dini ini juga tertuang pada Undangundang Sistem Pendidikan Nasional No.20 tahun 2003. Oleh karena itulah kita sebagai guru dan orang tua harus bisa bekerjasama dalam mendidik dan menstimulasi semua aspek perkembangan anak tersebut. Sehingga kedepannya kita bisa menghasilkan SDM yang baik dalam membangun negara yang kita cintai ini.

Selama proses pendidikan, orang tua sangat antusias dalam memberikan pelayanan kepada anak untuk siap berangkat kesekolah dan menjemput anak pulang sekolah serta mempersiapkan semua kebutuhan anak yang diminta oleh pihak sekolah termasuk administrasi yang harus dipenuhi. Orang tua mengungkapkan bahwa yang penting baginya anak dimasukkan kelembaga PAUD supaya saat masuk SD nanti anak sudah bisa membaca, menulis dan berhitung serta mengaji. Setelah itu orang tua sibuk dengan pekerjaan masing-masing tanpa menghiraukan seperti apa perkembangan sosial emosionalnya selama berada di sekolah.

Guru sebagai pendidik yang profesional sudah ditempa dengan berbagai ilmu pendidikan dan pelatihan-peatihan bagaimana cara yang baik dalam memberikan pelayanan kepada anak selama berada di lembaga PAUD. Walaupun sudah di asah keilmuannya selaku manusia tentu punya batas kemampuan dalam memberikan pelayanan jika anak yang dilayani di lembaga PAUD banyak memperlihatkan perilaku-perilaku yang tidak sesuai dengan perkembangannya, seperti: suka mengganggu teman, suka meribut saat proses pembelajaran, suka memukul teman dan lain sebagainya. Seharusnya pada usia 5-6 tahun ini perkembangan sosial emosional anak sudah berkembang sesuai tahap-tahap perkembangannya. Akan tetapi dengan bertambahnya usia serta anak tumbuh dan berkembang distimulasi oleh lingkungan, maka sosial emosional anak sangat dipengaruhi juga oleh lingkungan terutama lingkungan keluarga. Untuk itu keluarga harus bisa memberikan pelayanan yang tepat pada anak terutama dalam perkembangan sosial emosional yang berujung pada pembentukan perilaku anak kearah yang lebih baik. Orang tua harus mampu memperlihatkan sikap sosial dan emosi yang baik sebagai model bagi anak dalam berperilaku.

Sejak lahir manusia memiliki salah satu potensi dan akan berkembang sesuai dengan lingkungannya yang disebut dengan emosi[1]. Emosi adalah perasaan yang ada dalam diri kita, dapat berupa perasaan senang atau tidak senang, perasaan baik atau buruk. Macam-macam perasaan tersebut adalah gambaran dari emosi. Emosi merupakan suatu suasana yang kompleks ( $a$ complex feeling state) dan getaran jiwa (stid up state) yang menyertai atau muncul sebelum atau sesudah terjadinya suatu perilaku[2]. Berdasarkan definisi tersebut kita dapat memahami bahwa emosi merupakan suatu keadaan yang kompleks, dapat berupa perasaan ataupun getaran jiwa yang ditandai oleh perubahan biologis yang muncul menyertai terjadinya suatu perilaku.

Perkembangan tingkah laku pada anak dimana anak diminta untuk menyesuaikan diri dengan aturan yang berlaku dalam lingkungan masyarakat disebut perkembangan sosial[3]. Perkembangan sosial juga merupakan pencapaian kematangan dalam hubungan sosial yang sangat bergantung pada individu anak, peran orang tua, dan lingkungan masyarakat[4]. Anak usia dini memiliki sifat egosentris dimana anak lebih mementingkan dirinya sendiri karena ia cendrung melihat dan memahami sesuatu dari sudut pandang mereka sendiri[5]. Hal ini menyebabkan mereka memiliki prilaku seperti berebut alat mainan, menangis jika kehendaknya tidak dituruti, 
memaksakan sesuatu kepada orang lain dsb.

Awal perkembangan sosial pada anak tumbuh dari hubungan anak dengan orang tua atau pengasuh dirumah terutama anggota keluarganya. Anak mulai bermain bersama orang lain yaitu keluarganya. Tanpa disadari anak mulai belajar berinteraksi dengan orang diluar dirinya sendiri yaitu dengan orang-orang disekitarnya. Interaksi sosial kemudian diperluas, tidak hanya dengan keluarga dalam rumah namun mulai berinteraksi dengan tetangga dan tahapan selanjutnya ke sekolah.

PAUD Terpadu Hauriyyah Halum merupakan salah satu PAUD yang berada di kota Padang. Sebagian besar orang tua memasukkan anaknya ke PAUD Terpadu Hauriyyah Halum dikarenakan ingin membekali anaknya pandai membaca, menulis, dan berhitung agar siap masuk SD. Orang tua tidak memperdulikan bagaimana perilaku anaknya di sekolah seperti suka memukul teman, mengganggu teman, tidak mau antri, meribut bahkan berkata-kata tidak baik. Hal ini menyebabkan para guru PAUD merasa kewalahan dalam menghadapi perilaku anak didiknya, padahal butuh kerjasama antara pihak guru dan wali murid dalam menstimulasi perkembangan sosial emosional anak usia dini. Oleh karena itu perlu diadakan penyuluhan kepada orang tua maupun guru PAUD tentang bagaimana keterlibatan orang tua dilembaga PAUD dalam menstimulasi perkembangan sosial emosional anak usia dini. Penyuluhan serupa telah dilaksanakan oleh Rani dkk terhadap penanganan anak berkebutuhan khusus[6], Sufa dkk untuk mengoptimalisasi peran orang tua dalam mengembangkan potensi PAUD[7], dan Fahruddin dkk dalam bentuk pelatihan program parenting untuk meningkatkan profesionalisme guru PAUD di Kota Mataram[8]. Untuk itu perlu dilaksanakan pengabdian berupa penyuluhan di sekolah PAUD Terpadu Hauriyyah Halum Kota Padang dengan tujuan agar baik guru PAUD maupun orang tua dapat menjalankan perannya masing-masing dan berkerjasama dalam menstimulasi perkembangan sosial emosional anak usia dini.

\section{METODE PELAKSANAAN}

Kegiatan pengabdian kepada masyarakat berupa penyuluhan yang diberikan kepada guru dan orang tua anak di PAUD Terpadu Hauriyah Halum dalam bentuk 2 metode, yaitu

\section{Metode Ceramah}

Dimana dalam penyuluhan nara sumber menyajikan bahan pengajaran atau materi melalui penerangan dan penuturan lisan oleh pemateri tentang suatu topik materi kepada peserta secara langsung. Penggunaan metode ini disertai dengan penggunaan media seperti laptop dan LCD agar kompetensi dan indikator ketercapaian materi dapat dicapai sehingga peserta memiliki pemahaman dan menerapkannya dalam kehidupan sehari-hari[9]. Adapun materi yang diberikan kepada peserta berkaitan dengan bentuk kerjasama guru dengan orang tua dalam menstimulasi perkembangan sosial emosional anak usia dini seperti dibawah ini.

a. Pelibatan orang tua pada program sekolah dalam menstimulasi perkembangan sosial emosional anak usia dini.

b. Pengaruh pendidikan keluarga terhadap perkembangan sosial-emosional anak

c. Cara menstimulasi perkembangan sosial-emosional anak

2. Metode Tanya Jawab

Dimana nara sumber menggunakan/memberikan pertanyaan kepada peserta dan peserta menjawab atau sebaliknya tentang materi yang telah disampaikan. Metode tanya jawab dapat 
meningkatkan keaktifan peserta, kemampuan berpikir kritis sehingga suasana terasa lebih hidup. Selain itu, metode ini dapat memberikan pengalaman dan masukan baik bagi pemateri maupun bagi peserta[10].

\section{HASIL}

Tim Dosen STKIP Adzkia melaksanakan pengabdian kepada masyarakat di sekolah PAUD Terpadu Hauriyyah Halum Kota Padang. Pengabdian ini dilaksanakan atas dasar permintaan dari pihak guru PAUD agar diberikan penyuluhan tentang pentingnya keterlibatan orang tua di lembaga PAUD dalam menstimulasi perkembangan sosial emosional anak usia dini. Penyuluhan dilaksanakan pada hari Sabtu tanggal 15 Februari 2020 di ruang pertemuan PAUD Terpadu Hauriyyah Halum dan diikuti oleh para orang tua atau wali murid dan guru sebanyak 25 orang.

Kegiatan penyuluhan ini dibuka oleh salah satu guru PAUD Terpadu Hauriyyah Halum. Penyuluhan diawali dengan penayangan vidio seperti apa bentuk-bentuk perilaku anak saat berada disekolah akibat pengasuhan yang diberikan oleh orang tua selama dirumah. Sehingga orang tua mengetahui tujuan dari penyuluhan ini diberikan supaya orang tua menyadari akan pentingnya pengasuhan yang tepat kepada anak serta termotivasi untuk berperilaku baik dalam kehidupan sehari-hari dihadapan anak.
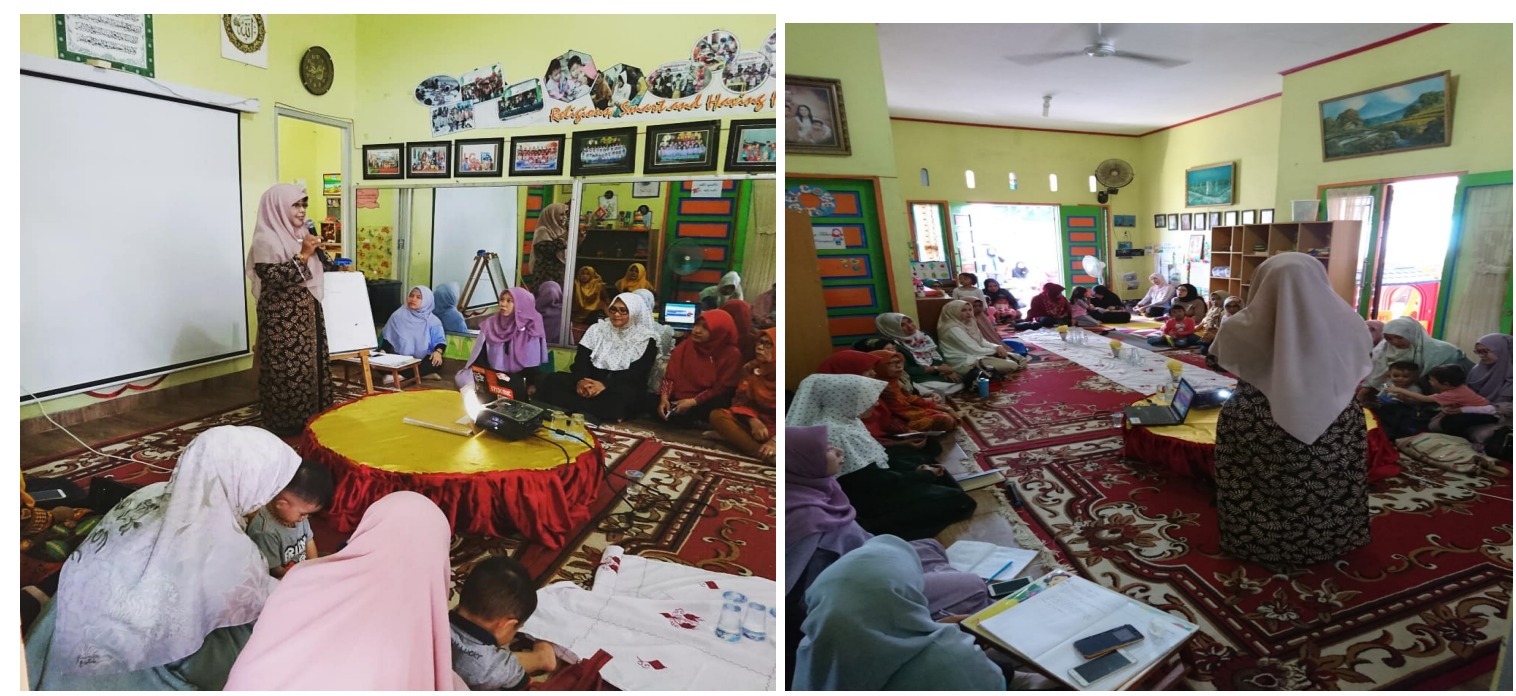

Gambar 1. Penyampaian materi oleh narasumber

Pada gambar 1, narasumber Ibu Evi Desmariani, M.Pd menyampaikan materi penyuluhan tentang pentingnya keterlibatan orang tua dilembaga PAUD dalam menstimulasi perkembangan sosial emosional anak usia dini. Narasumber memberikan contoh secara langsung didepan peserta seperti apa fenomena yang terjadi saat ini pengasuhan yang salah diberikan orang tua sehingga mampu menstimulasi perkembangan sosial emosional anak yang tidak baik selama proses pembelajaran disekolah. 


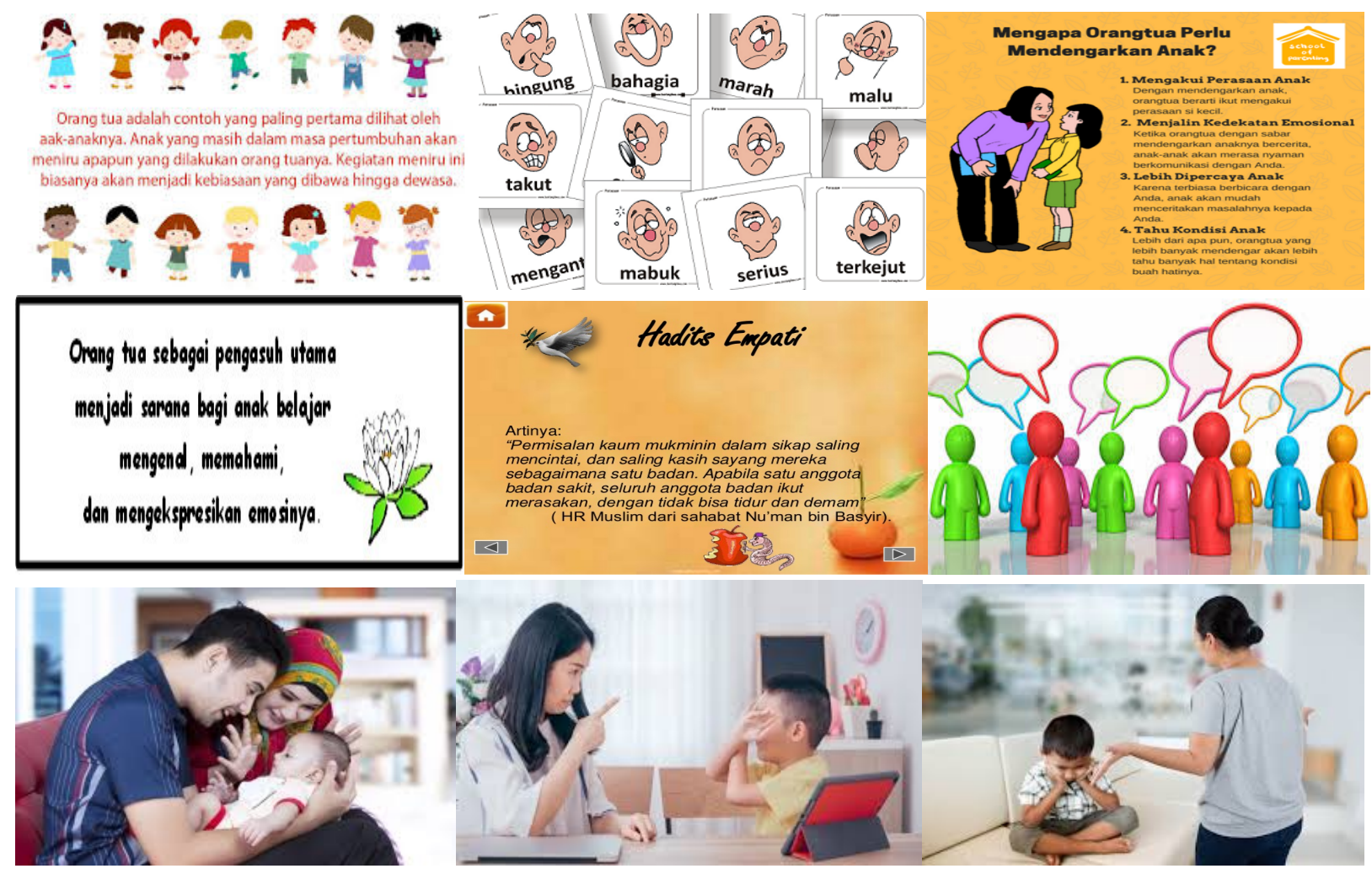

Gambar 2. Materi yang disampaikan oleh narasumber

Gambar 2 merupakan kumpulan materi yang disampaikan oleh narasumber, mulai dari pentingnya pelibatan orang tua pada program sekolah dalam menstimulasi perkembangan sosial emosional anak usia dini, beberapa upaya yang dapat dilakukan orang tua dalam mengembangkan sosial dan emosional anak usia dini, dan pengaruh pendidikan keluarga terhadap perkembangan sosial-emosional anak seperti menunjukkan kasih sayang kepada anak, mendorong anak untuk mencoba hal baru, memperkenalkan anak dengan teman sebayanya, memperlihatkan perasaan dengan jelas, membangun rasa percaya anak, dan membangun kemandirian anak. Selain itu, narasumber juga mengajarkan cara menstimulasi perkembangan sosial emosinal anak seperti orang tua dan guru harus menjadi contoh yang baik, mengajarkan pengenalan emosi, menanggapi dan memahami perasaan anak, melatih pengendalian diri dan mengelola emosi, menerapkan disiplin dengan konsep empati, melatih keterampilan komunikasi dan sosial, memberi iklim positif, tidak menabukan marah, sedih dan cemas, mengajari akibat perilaku, dan memberikan reinforcement (penguatan) atas perilaku anak yang positif.

Setelah narasumber menyampaikan materi dengan metode ceramah, dilanjutkan dengan sesi tanya jawab dimana nara sumber menggunakan/memberikan pertanyaan kepada peserta dan peserta menjawab atau sebaliknya peserta bertanya kepada nara sumber dan nara sumber menjawab pertanyaan peserta terkait seperti apa bentuk kerjasama guru dan orang tua dalam menstimulasi perkembangan sosial emosional anak usia dini. Degan adanya kegiatan tanya jawab terjadi aktivitas interaksi timbal balik antara orang tua dan guru sehingga cakrawala orang tua bertambah dan berusaha untuk merubah berbagai perilaku dalam mendidik anak di rumah. Semua aktivitas orang tua terbuka dan tidak hal yang tersembunyi sehingga dapat dicarikan solusinya secara bersama-sama. 


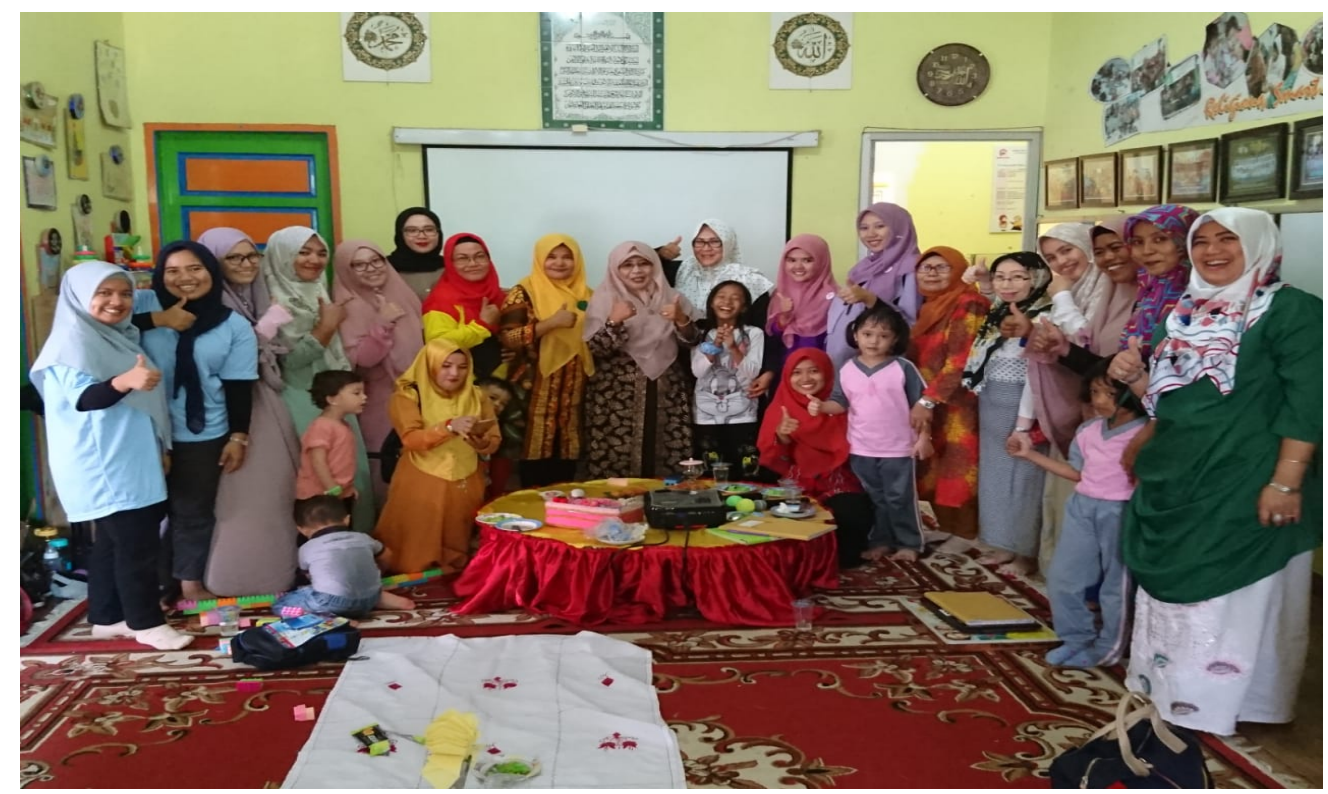

Gamnbar 3. Foto bersama antara tim pengabdian dengan peserta

Pada akhir penyuluhan dilakukan foto bersama tim dosen pengabdian kepada masyarakat STKIP Adzkia dengan para peserta penyuluhan seperti pada gambar 3. Berdasarkan wawancara, tanya jawab dan pengamatan langsung selama kegiatan berlangsung, kegiatan pengabdian pada masyarakat ini memberikan hasil sebagai berikut:

a. Meningkatnya pengetahuan dan pemahaman orang tua terkait materi penyuluhan pentingnya keterlibatan orang tua di lembaga PAUD dalam menstimulasi perkembangan sosial emosional anak usia dini.

b. Meningkatnya kemampuan guru untuk bisa menjalin kerjasama yang baik dengan orang tua atau wali murid dalam memberikan pelayanan kepada anak selama berada di sekolah untuk menstimulasi perkembangan sosial emosional anak usia dini.

Beberapa faktor yang mendukung terlaksananya kegiatan pengabdian pada masyarakat ini adalah besarnya minat, semangat dan antusiasme peserta selama kegiatan, sehingga kegiatan berlangsung dengan lancar dan penuh makna. Sedangkan faktor penghambatnya adalah keterbatasan waktu penyuluhan. Target peserta penyuluhan seperti direncanakan sebelumnya adalah semua orang tua dapat hendaknya berusaha membiasakan menampilkan perilaku yang baik dalam kehidupan sehari-hari di hadapan anak selama berada di rumah. Sehingga saat anak berada dimana saja perilaku yang baik tersebut akan dibiasakannya dalam dunia bermain dengan teman sebaya. Akhirnya anak akan memperlihatkan perkembangan sosial emosional yang baik sesuai tahap perkembangannya. Dari jumlah peserta yang hadir menunjukkan bahwa kegiatan pengabdian kepada masyarakat dikatakan cukup berhasil karena dihadiri 25 orang. Kekurangan dari daya serap peserta dalam menerima penyuluhan ini disebabkan oleh kemampuan peserta yang berbeda-beda. akan tetapi antusias yang sangat tinggi terlihat dari keterlibatan peserta dalam mengikuti penyuluhan serta perannya dalam membantu terselenggaranya kegiatan ini. Setiap kekurangan yang nampak menjadi masukan bagi tim untuk melakukan yang lebih baik dari persiapan maupun komunikasi dengan pihak sekolah yang dapat dijadikan sebagai pertimbangan dalam melakukan kegiatan pengabdian kepada masyarakat pada tahun-tahun yang akan datang.

\section{KESIMPULAN}


Kegiatan pengabdian kepada masyarakat ini dapat disimpulkan bahwa:

1. Pengetahuan dan pemahaman para orang tua mengenai pentingnya keterlibatan orang tua di lembaga PAUD dalam menstimulasi perkembangan sosial emosional anak usia dini semakin meningkat dengan adanya kegiatan tanya jawab antara orng tua dan guru. Semua aktivitas yang dilakukan terekam dengan baik dan dapat dicarikan solusinya.

2. Kerjasama yang baik antara guru dengan orang tua semakin meningkat melalui keterlibatan orang tua dalam setiap kegiatan yang dilaksanakan terutama dalam menstimulasi perkembangan sosial emosional anak usia dini.

3. Anak semakin mendapat perhatian yang baik dari orang tua sehingga guru terbantu dan guru tidak kewalahan dalam mengajar anak di sekolah.

Mengingat besarnya manfaat kegiatan pengabdian kepada masyarakat ini, maka selanjutnya perlu:

1. Mengadakan penyuluhan yang serupa pada lembaga PAUD yang lain terkait pentingnya keterlibatan orang tua di lembaga PAUD dalam menstimulasi perkembangan sosial emosional anak usia dini.

2. Adanya kesinambungan dan monitoring program setelah kegiatan pengabdian ini sehingga para wali murid di PAUD Terpadu Hauriyyah Halum benar-benar dapat mengaplikasikan pengetahuan cara menstimulasi perkembangan sosial emosional anak semenjak usia dini selama berada di rumah.

\section{DAFTAR PUSTAKA}

[1] E. M. HM, “Mengelola kecerdasan emosi," Tadrib, vol. 2, no. 2, pp. 198-213, 2016.

[2] A. Syamsuddin, "Psikologi Pendidikan (Edisi Revisi)," Bandung: Remaja Rosda Karya, 2000.

[3] F. Nurmalitasari, "Perkembangan sosial emosi pada anak usia prasekolah," Bul. Psikol., vol. 23, no. 2, pp. 103-111, 2015.

[4] F. Mayar, "Perkembangan sosial anak usia dini sebagai bibit untuk masa depan bangsa," Al-Ta lim J., vol. 20, no. 3, pp. 459-464, 2013.

[5] A. Priyanto, "pengembangan kreativitas pada anak usia dini melalui Aktivitas bermain," $J$. Ilm. Guru Caraka Olah Pikir Edukatif, no. 2, 2014.

[6] K. Rani and M. N. Jauhari, "Keterlibatan orangtua dalam penanganan anak berkebutuhan khusus," J. Abadimas Adi Buana, vol. 2, no. 1, pp. 55-64, 2018.

[7] F. F. Sufa and M. H. Y. Setiawan, "OPTIMALISASI PERAN ORANGTUA DALAM MENGEMBANGKAN POTENSI PAUD,” Adi Widya J. Pengabdi. Masy., vol. 2, no. 2, pp. 178-184, 2018.

[8] F. Fahruddin and B. N. Astini, "Pelatihan Program Parenting untuk Meningkatkan Profesionalisme Guru PAUD Di Kota Mataram Tahun 2018," J. Pengabdi. Magister Pendidik. IPA, vol. 1, no. 1, pp. 37-44, 2018.

[9] S. Tambak, "Metode Ceramah: Konsep dan Aplikasi dalam Pembelajaran Pendidikan Agama Islam," J. Tarb., vol. 21, no. 2, pp. 375-401, 2014.

[10] N. Huda, "Penerapan metode tanya jawab sebagai upaya meningkatkan keaktifan siswa pada mata pelajaran fiqih kelas X IPA 3 MA Darussalam Krempyang Tanjunganom Nganjuk,” J. El-Barqie J. MA Darussalam, vol. 1, no. 1, pp. 141-162, 2020. 